\title{
Running Safety of Trains under Vessel-Bridge Collision
}

\author{
Yongle Li, ${ }^{1}$ Jiangtao Deng, ${ }^{1,2}$ Bin Wang, ${ }^{1}$ and Chuanjin Yu ${ }^{1}$ \\ ${ }^{1}$ Department of Bridge Engineering, Southwest Jiaotong University, No. 111, North 1st Section of Second Ring Road, \\ Chengdu 610031, China \\ ${ }^{2}$ The Third Railway Survey and Design Institute Group Co., Ltd., Tianjin 300142, China
}

Correspondence should be addressed to Yongle Li; lele@swjtu.edu.cn

Received 11 August 2014; Revised 13 December 2014; Accepted 14 December 2014

Academic Editor: Ting-Hua Yi

Copyright (C) 2015 Yongle Li et al. This is an open access article distributed under the Creative Commons Attribution License, which permits unrestricted use, distribution, and reproduction in any medium, provided the original work is properly cited.

\begin{abstract}
To optimize the sensor placement of the health monitoring system, the dynamic behavior of the train-bridge system subjected to vessel-collision should be studied in detail firstly. This study thus focuses on the characteristics of a train-bridge system under vesselbridge collision. The process of the vessel-bridge collision is simulated numerically with a reliable finite element model (FEM). The dynamic responses of a single car and a train crossing a cable-stayed bridge are calculated. It is shown that the collision causes significant increase of the train's lateral acceleration, lateral wheelset force, wheel unloading rate, and derailment coefficient. The effect of the collision on the train's vertical acceleration is much smaller. In addition, parametric studies with various train's positions, ship tonnage, and train speed are performed. If the train is closer to the vessel-bridge collision position or the ship tonnage is larger, the train will be more dangerous. There is a relatively high probability of running danger at a low speed, resulting from longer stay of the train on the bridge. The train's position, the ship tonnage, and the train speed must be considered when determining the most adverse conditions for the trains running on bridges under vessel-bridge collision.
\end{abstract}

\section{Introduction}

Nowadays, health monitoring plays a very important role in assessing the performances of the civil infrastructures [14]. Meanwhile, with the growth of waterway and land transportation, the possibility of vessel-bridge collision increases significantly. To ensure the safety of both bridges and the trains moving on at the occasion of vessel-bridge collision, health monitoring system (HMS) can be installed to monitor the behavior of the trains and bridges in real time [5]. To utilize HMS and distribute the sensors in a rational way, the performances and characteristics of train-bridges system under vessel-bridge collision should be studied firstly as significant references. This study thus focuses on the characteristics of train-bridge interaction under ship collision, which will be beneficial to HMS.

In the study of vessel-bridge collision, available researches have been carried out with emphasis on the force and probability of vessel-bridge collision, structural damage, anticollision device, and FEM simulation [6-8]. Some empirical formulations were presented by Pedersen and Zhang [9], which related the energy absorbed by the crushing of ship structures to the maximum impact loads between the ship structure and a bridge pier or girder. A simulation calculation method of vessel-collision was studied by Liang and Cheng [10], which was based on the discussion about the kinetic theory of vessel-collision. The collision force can be known from the deformative force of the springs. Yetal [11] analyzed the vessel-bridge collisions at Japanese coastal strait and concluded that it occurs more likely during daytime rather than evening or the smaller visibility in heavy fog. Employing a statistical method, the vessel-bridge collision possibility was gained in $0.7 \times 10^{-6} \sim 59 \times 10^{-6}$ in six Europe main watercourses (including rivers and straits) [12]. The commonly used probability models for the vessel-bridge collision are AASHTO model [13], European specification model [14], KUNZI model [15], and IABSE model [16]. Numerical simulations carried out by Chen et al. [17] showed that the energy transform, distortion, and stress distribution in the bridge under collision fitted well with the data from field test. The ADINA finite-element code was used by Consolazio and Cowan [18] to compute the force-deformation relationships 
for several hopper barge crushing scenarios. Results obtained from the nonlinear finite-element crush analyses were then compared with the empirical crush models found in bridge design specifications.

A scenario of a 12000 DWT bulk cargo collision with a bridge pier was simulated by Wang and Chen [19]. The time history of the ship collision force and the damage of the bridge pier were presented. It was shown that the peak value of ship collision force decreased remarkably due to the failure of concrete. A numerical methodology, performed with an explicit finite-element program, was employed by Lenselink et al. [20] to simulate the dynamic events of collisions where a double hull tanker was struck by another ship. Numerical analysis of vessel-bridge collision was studied by Lehmann and Peschmann [21], of which the angle deviated by about $3^{\circ}$ from the perpendicular direction, leaving the mass of the ship and the effect of the moving water out of consideration. An alternative approach was proposed by Pedersen and Zhang [9]. The nonlinear barge and pier responses were coupled together by a shared collision impact force. And numerical procedures were adopted to accelerate the convergence of calculation. Nonlinear finite-element analysis of barge collision with a single bridge pier was performed by Sha and Hao [22].

A lot of analyses on ships or bridges, about the static and dynamic vessel-bridge collision force, were performed as reviewed above. However, it is extremely rare to choose the moving trains as the subject and explore the dynamic response of trains under vessel-bridge collision. For the safety of trains moving on bridges, a dynamic model of coupled train-bridge system is established by Xia et al. [23] to investigate the critical train speeds for running safety subjected to earthquakes. With a model of railway-bridge-system, the dynamic stability of trains moving over bridges shaken by earthquakes is studied by Yang and $\mathrm{Wu}$ [24]. Regarding the vessel-bridge collision force as one type of collision loads, Xia et al. [25] discussed the running safety of trains subjected to the collision, in which the influence of the train's position, the tonnage of the ship, and the speed of the train was ignored. Numerical analysis of ship-bridge collision's influences on the running safety of moving rail train was performed by Zhang et al. [26], discussing the effects of train speed and the momentum of impacting ship on the running safety of the rail train. But the influence of the train's position was ignored. Actually, those factors are significant to install the HMS and their effects should be studied in detail.

In this paper, the response history of a single train and a train set crossing a bridge under vessel-bridge collision is investigated. The train's position, the tonnage of the ship, and the speed of the train are involved in parameter studies. The conclusion can provide scientific basis for HMS to monitor the behavior of moving vehicles on bridges under vesselbridge collision.

\section{Force during Vessel-Bridge Collision}

2.1. FEM of Vessel-Bridge Collision. A railway cable-stayed bridge (see Figures 1 and 2) and a common bulk carrier are

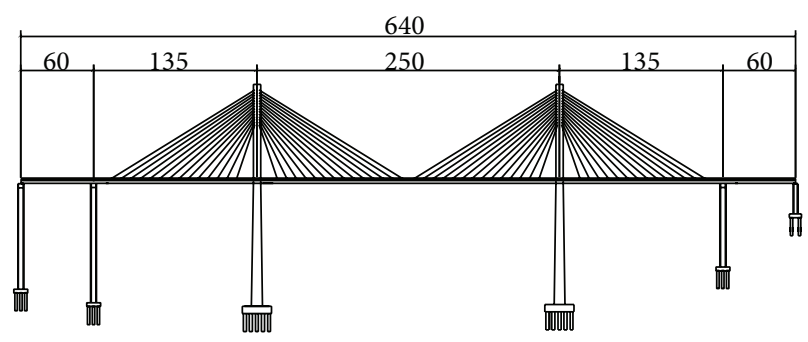

FIGURE 1: General arrangement of the cable-stayed bridge (unit: m).
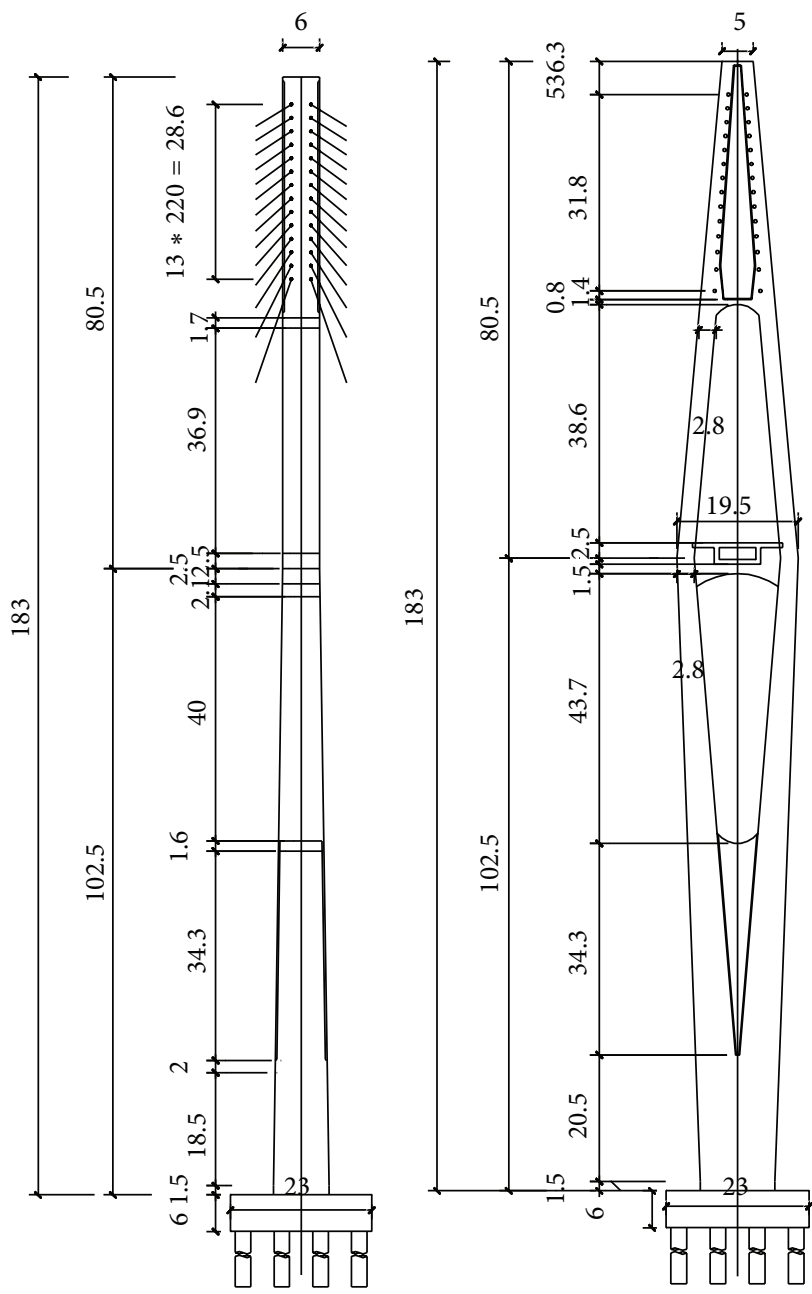

Figure 2: Pylon of the bridge (unit: $\mathrm{m}$ ).

taken as an example. The bridge is a double-pylon cablestayed bridge with a length of $640 \mathrm{~m}$ and a main span of $250 \mathrm{~m}$. The height of its pylons is $183 \mathrm{~m}$ and the height of the up part of the pylons above the average water lever is $89.5 \mathrm{~m}$. The length, width, depth, summer load line, and weight of the ship are $93.93 \mathrm{~m}, 15.00 \mathrm{~m}, 6.70 \mathrm{~m}, 5.4 \mathrm{~m}$, and $3500 \mathrm{t}$, respectively. And the thickness of the plate of the bow is $10 \mathrm{~mm}$. A reliable 3D model of the ship and bridge is built using the software LS-DYNA. Plate elements are used to model the bow 
while rigid plate elements ignoring deformations are adopted to simulate the stern of the ship. Mesh density becomes higher for the ship model from the stern to the bow. The maximum element size is $1000 \mathrm{~mm}$ while the minimum one is $80 \mathrm{~mm}$. Totally, there are 78616 nodes, 79705 quadrilateral plane elements, and 3236 triangular plane elements. Figure 3 shows the FEM of the ship. The bridge pylon is assumed as a rigid-wall model. Figure 4 shows the FEM for both the ship and the bridge, where the girders and piers are all described by using the beam 4 elements, to model the process of vesselbridge collision.

2.2. Calculated Collision Force. In the simulation, the ship collides with the bridge pylon with a speed of $3 \mathrm{~m} / \mathrm{s}$. Figure 5 shows the dynamic process of the vessel-bridge collision. The collision course can be divided into 3 stages. At the first stage, the up deck and the taper surface of the ship collide with the bridge pylon. In the second stage, the bulbous bow collides with the bridge pylon. And the maximum collision force appears in this stage. Then, the collision force reduces with the crushing of the up deck, the taper surface, and the bulbous bow. The third stage is caused by the material hardening of the ship, resulting in the fact that the collision force reaches to a second peak. Then the collision force decays quickly until the collision is over. The time history of the collision force is shown in Figure 6. The maximum collision force is $13.83 \mathrm{MN}$ at $0.63 \mathrm{~s}$, which is between the 0.3 and 0.6 times of the calculated collision force by the railway standard in China. Moreover, the collision process lasts $1.9 \mathrm{~s}$, starting from just a contact of the ship to the bridge pylon. It can also be shown in Figure 6 that there are two peaks in the time history curve of the collision force. Unloading, failure, and damage of the ship appear between the two peaks. Figure 7 shows a sketch of the deformation of the bridge under the collision force. Besides, the maximum impact force in the previous work [26], where a 2000 DWT ship impact onto a pile cap with an initial velocity of $4 \mathrm{~m} / \mathrm{s}$ was simulated, was 11.2 MN. Compared with this, the result of maximum impact force is reasonable, considering there are differences among the tonnage and the velocity of the ship and the size of the bridge.

\section{Responses and Running Safety of Trains under Vessel-Bridge Collision}

To consider the coupled dynamics between the trains and the bridge, the responses and running safety of trains are investigated based on the coupled vehicle-bridge vibration with the analysis software BANSYS [27] (bridge analysis system). CRH2 passenger train is set with arrangement of 2 $\times(1$ trailer +1 motor +1 motor +1 trailer $)$. And the basic parameters of CRH2 are shown in Table 1. German track spectrum with low interference is adopted to simulate the track irregularity, and the space interval of the dynamic time history analysis is $0.2 \mathrm{~m}$. The bridge is made of concrete with a damping ratio of $2.0 \%$. The evaluation indices for the running safety of the train currently used in Ministry of Railways of the PRC [6] are about the derailment factor $Q / P_{1}$ (defined

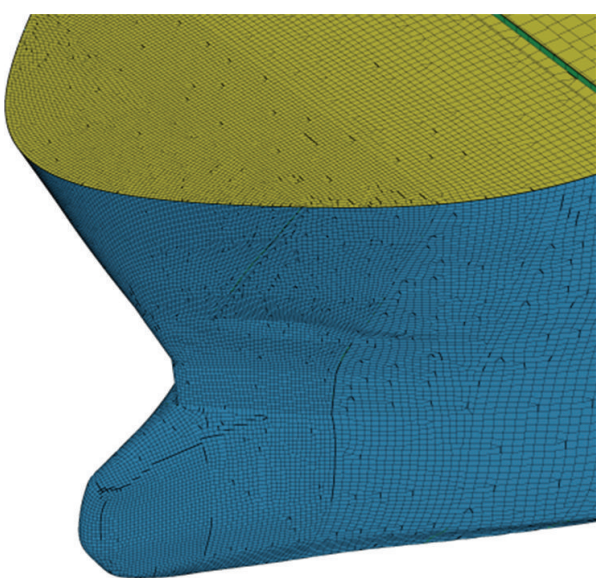

FIgURE 3: FEM for the ship.

TABLE 1: Basic parameters of CRH2.

\begin{tabular}{lcccccc}
\hline \multirow{2}{*}{ Vehicle type } & & Weight/t & \multicolumn{3}{c}{ Yawing inertia/t.m ${ }^{2}$} \\
& Body & Wheelset & Bogie & Body & Wheelset & Bogie \\
\hline Motor & 39.60 & 2.00 & 3.20 & 1900 & 0.980 & 3.20 \\
Trailer & 34.10 & 2.10 & 2.60 & 1700 & 1.029 & 2.60 \\
\hline
\end{tabular}

as the ratio of the lateral wheel-rail force $Q$ to the vertical wheel-rail force $P_{1}$ ) and the wheel unloading rate $\Delta P / P_{2}$ (defined as the ratio of the offload vertical wheel-rail force $\Delta P$ to the static vertical wheel-rail force $\left.P_{2}\right)$. The allowable values of the indices are $Q / P_{1} \leq 0.8$ and $\Delta P / P_{2} \leq 0.6$.

3.1. Verification. BANSYS can be used to model the coupled behavior between the trains and the bridge. To verify the application of BANSYS to impact analysis, the responses of the bridge under the collision force are solved firstly and compared with the calculated results from the common software LS-DYNA. With the action of the collision force, the lateral bridge displacement curves, calculated after collision in $8 \mathrm{~s}$ by BANSYS and LS-DYNA, are compared in Figures 8 and 9. In general, the displacement curves tend to be the same, which indicates that BANSYS used in the collision analysis has realization feasibility. The lateral displacement, generated by the collision force of the ship, reaches maximum value after the collision. In pace with the vessel falling off from the bridge, the movement of the whole bridge is in free vibration and decays gradually.

\subsection{Responses of a Single Car under Vessel-Bridge Collision.} The motor of CRH2 is employed to investigate the responses of a single car under the vessel-bridge collision. Two positions $X_{1}$ and $X_{2}$ are defined to illustrate the results conventionally. $X_{1}$ is the collision location on the girder in the longitudinal direction of the bridge. $X_{2}$ is the location of the head of the train related to the collision location as the vesselbridge collision. And the positive coordinate direction is the advancing direction of the train, and the collision position is regarded as the origin, which means $X_{1}=0$. 


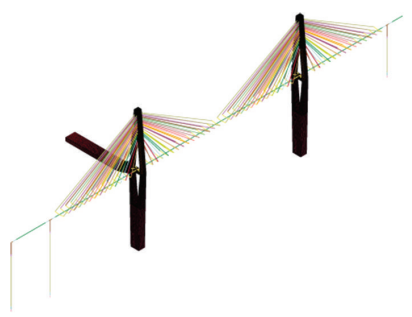

(a)

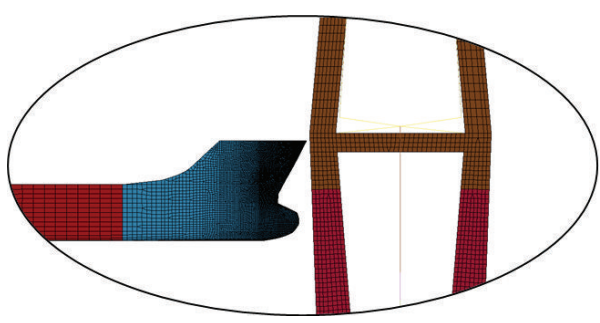

(b)

FIGURE 4: FEM for the vessel-bridge collision.

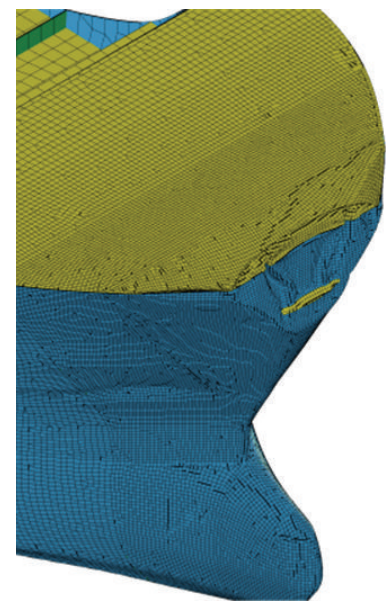

First stage

(a)

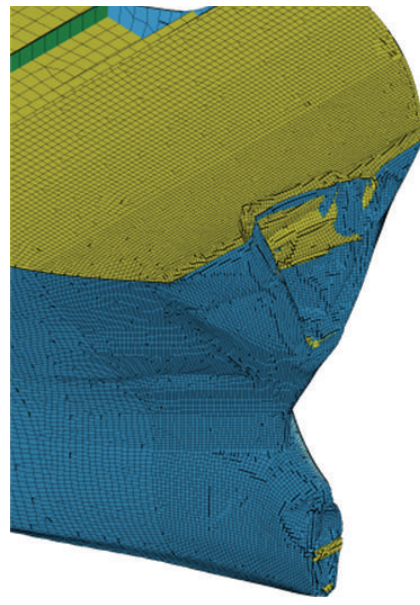

Second stage

(b)

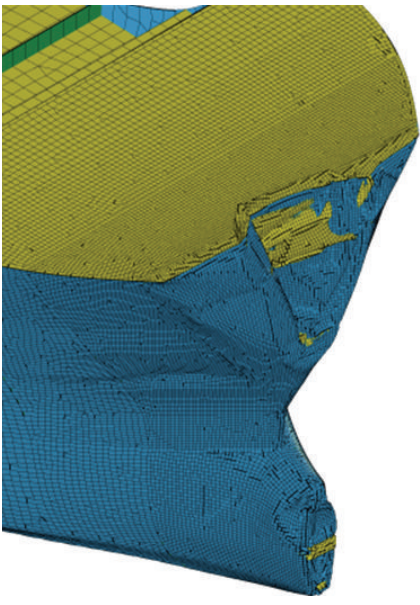

Third stage

(c)

FIgURe 5: Dynamic process of the vessel-bridge collision.

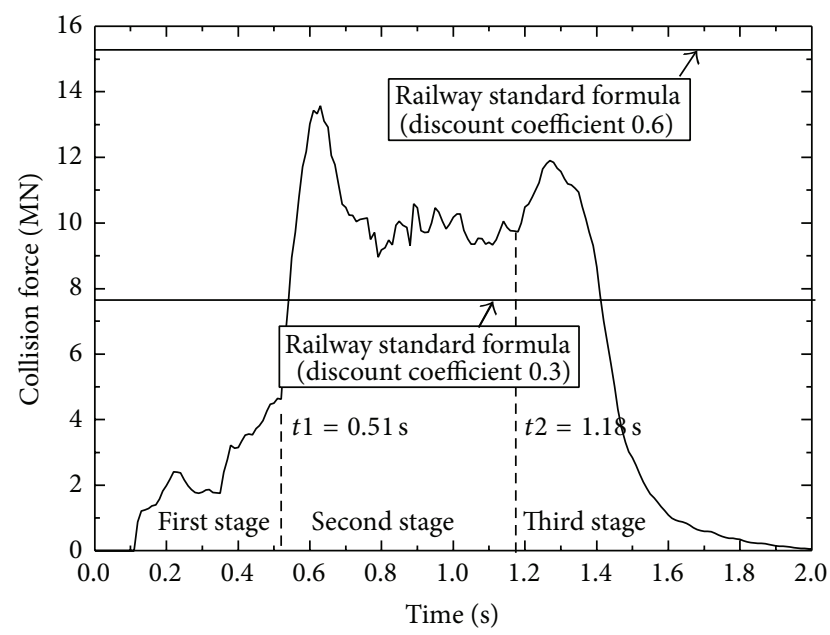

Figure 6: Time history curve of the collision force.

The motor moves with a speed of $80 \mathrm{~km} / \mathrm{h}$. In the down direction (the train moves from the right to the left), when $X_{2}$ is $-385 \mathrm{~m}$, the collision happens as the head of the train arrives at point D in Figure 10. The calculation condition is explained in more detail in Table 2. The corresponding lateral

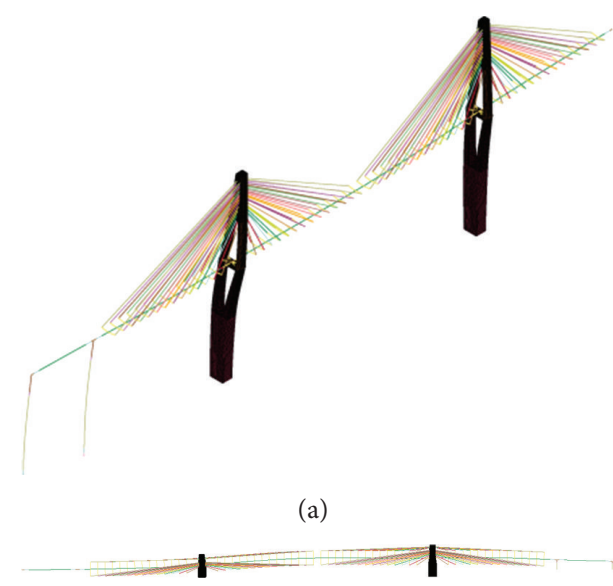

(b)

FIGURE 7: Deformation of the whole bridge under collision (amplified 100 times).

displacement curves of the bridge girder at different locations (points A, B, C, D, and E) are also shown in Figure 10. And the lateral displacement field of the whole bridge in the down direction is described in Figure 11. 
TABLE 2: Calculation condition of a single car (motor).

\begin{tabular}{lccc}
\hline The direction into the bridge & $X_{2}(\mathrm{~m})$ & $\begin{array}{c}\text { The distance between the } \\
\text { train and the collision } \\
\text { position }(\mathrm{m})\end{array}$ & Vehicle type \\
\hline Up (close to the collision position) & -385 & 385 & A single train of CRH2
\end{tabular}

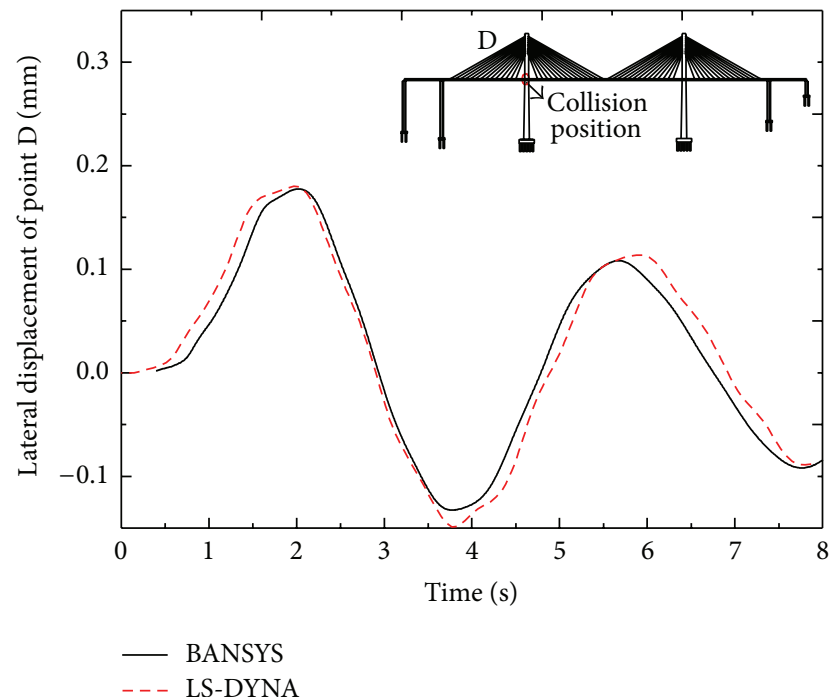

FIGURE 8: Lateral displacement of the girder at the collision position.

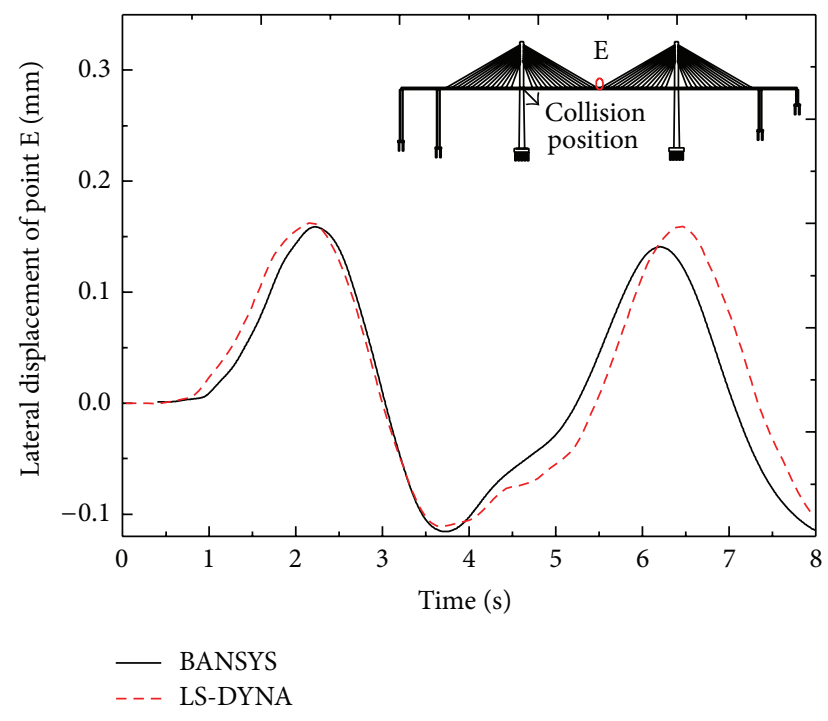

FiguRE 9: Lateral displacement of the girder in the mid-span.

For the motor, the lateral force, wheel unloading rate, and derailment coefficient of the first wheelset are shown in Figure 12. As shown in Figure 12, the collision force causes significant increase of the train's lateral acceleration, lateral wheelset force, wheel unloading rate, and derailment coefficient. However the effect of the collision force on the single car's vertical acceleration is much smaller.

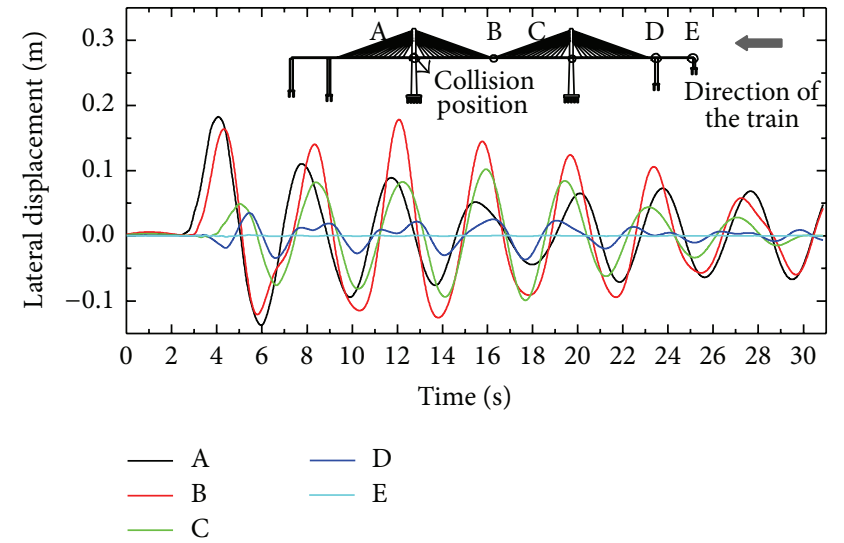

FIGURE 10: Lateral displacement calculated (in the down direction).

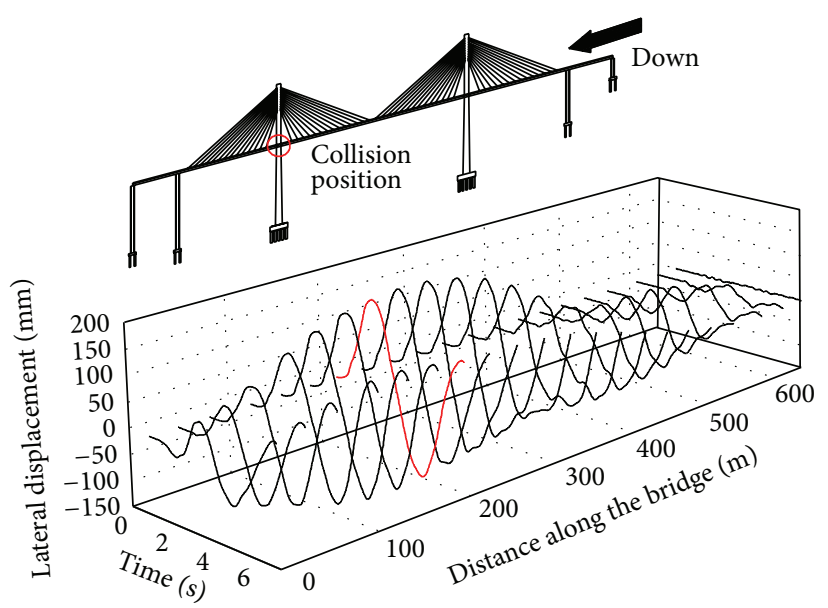

FIGURE 11: Lateral displacement field (in the down direction).

3.3. Responses of a Train under Vessel-Bridge Collision. The train passing by the bridge with $X_{2}=-195 \mathrm{~m}$ in the up direction with a speed of $80 \mathrm{~km} / \mathrm{h}$ is analyzed. The corresponding calculation condition is listed in Table 3. The time history curves of the lateral and vertical acceleration, the first wheelset force, the wheel unloading rate, and derailment coefficient of the first car, the trailer, and the sixth car, the motor, are shown in Figures 13 and 14. Figure 13 illustrates the time history curves of the responses of the first car, the trailer. When the train arrives at the entrance of the bridge and the collision happens at the same time, the maximum value of the trailer's lateral acceleration appears at $2 \mathrm{~s}$ and reaches 
TABLE 3: Calculation condition of a train (in the up direction).

\begin{tabular}{lccc}
\hline The direction into the bridge & $X_{2}(\mathrm{~m})$ & $\begin{array}{c}\text { The distance between the } \\
\text { train and the collision } \\
\text { position }(\mathrm{m})\end{array}$ & Vehicle type \\
\hline Up (close to the collision position) & -195 & 195 & A train set of CRH2 \\
\hline
\end{tabular}
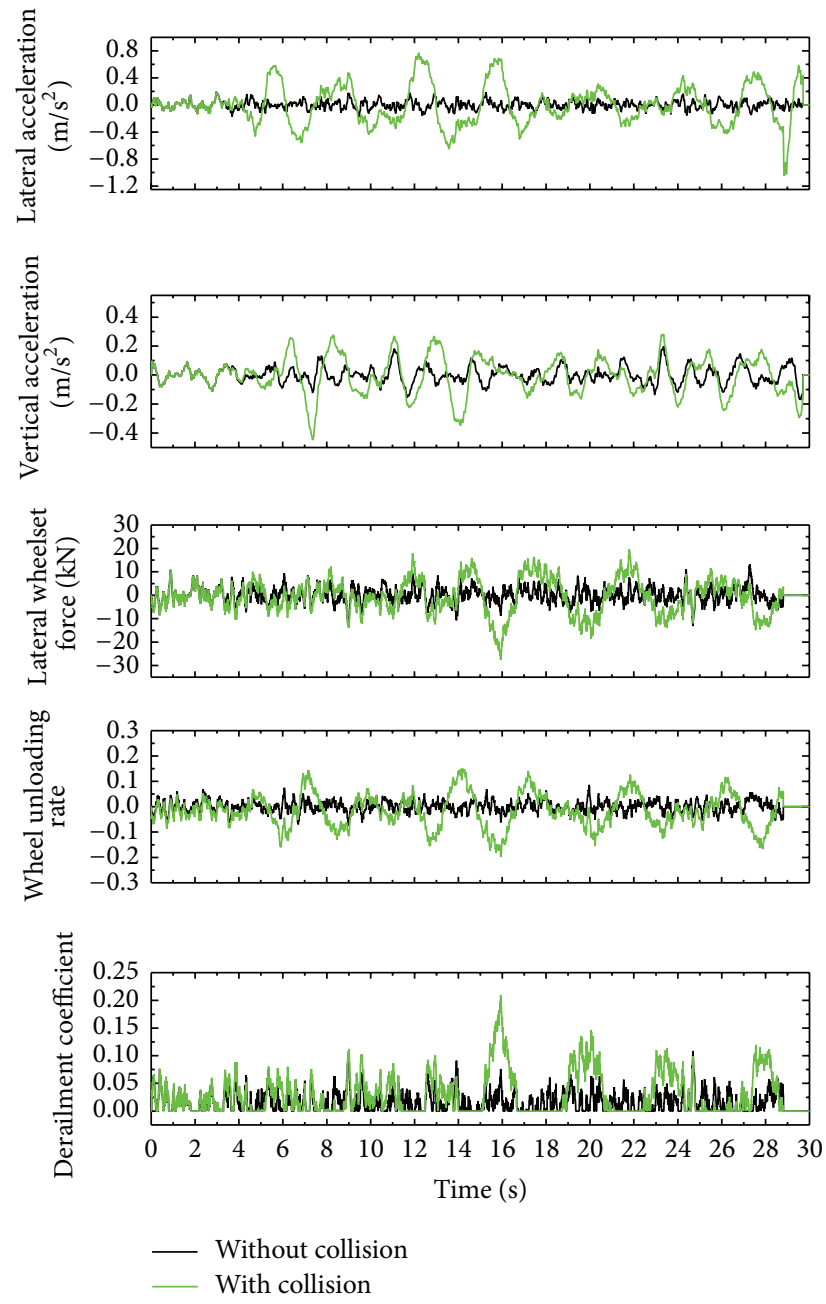

FIGURE 12: Responses of a single car $\left(X_{2}=-385 \mathrm{~m}, 80 \mathrm{~km} / \mathrm{h}\right.$, in the down direction).

$1.016 \mathrm{~m} / \mathrm{s}^{2}$, which is 3.89 times that without the collision. In addition, the maximum values of the first wheelset force, the wheel unloading rate, and derailment coefficient of the trailer are $2.34,2.37$, and 1.7 times those without the collision, respectively. But the trailer's vertical acceleration has little change with and without the collision.

German track spectrum is adopted to simulate the track irregularity in the paper, which is independent of the collision and the motion of the train. The resultant irregularity input into analysis model is the combination of the simulated irregularity and the bridge deformation. Since the model of the approach bridge is not established, the deformation of
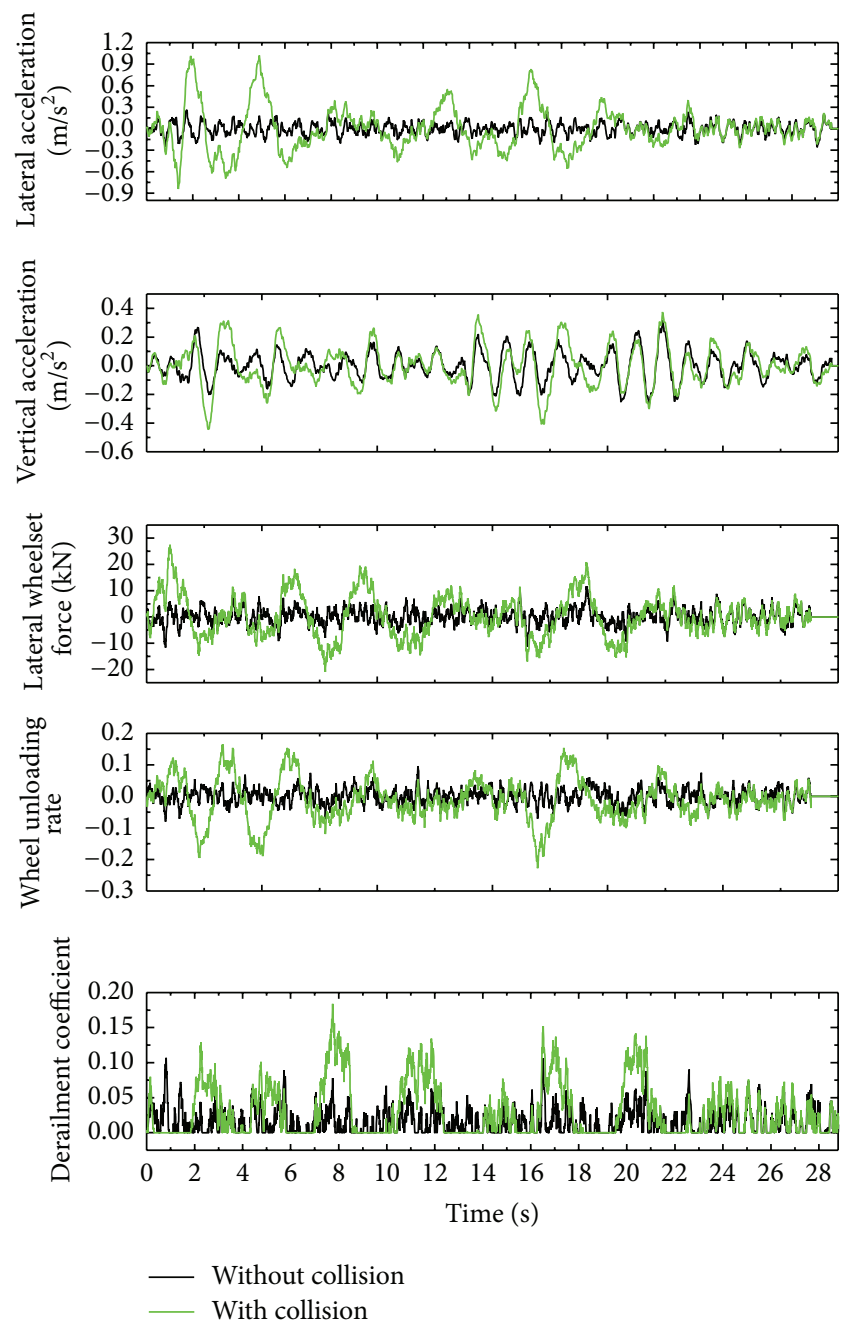

FIGURE 13: Responses of the trailer (the first train, $X_{2}=-195 \mathrm{~m}$, $80 \mathrm{~km} / \mathrm{h}$, in the up direction).

approach bridge is regarded as 0 . Thus the bridge deformation could increase from 0 to a certain value suddenly at the entrance of the main bridge if a train runs into the main bridge from the approach bridge, which can make the resultant irregularity change suddenly. The sudden change of the resultant irregularity can significantly enlarge the response of train, which is the reason why there are obvious responses of the train at the entrance or exit of the bridge.

Figure 14 illustrates the time history curves of the responses of the sixth train, the motor car, in the up direction. The motor's lateral acceleration reaches the maximum value in $5.85 \mathrm{~s}$ after the collision. 
TABLE 4: Calculation condition of a train (in the down direction).

\begin{tabular}{lccc}
\hline The direction into the bridge & $X_{2}(\mathrm{~m})$ & $\begin{array}{c}\text { The distance between the } \\
\text { train and the collision } \\
\text { position }(\mathrm{m})\end{array}$ & Vehicle type \\
\hline Down (far from the collision position) & -445 & 445 & A train set of CRH2 \\
\hline
\end{tabular}
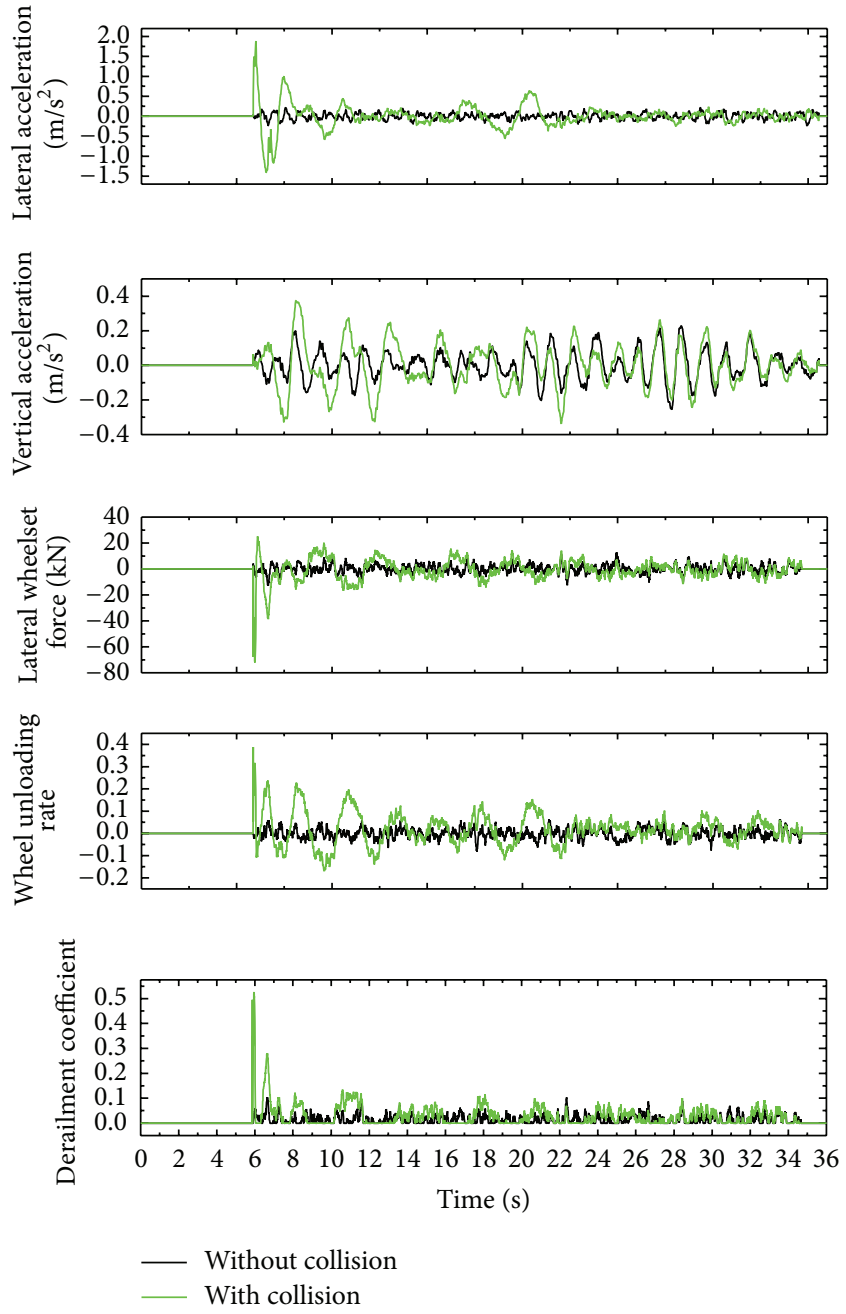

FIgURE 14: Responses of the motor car (the sixth train, $X_{2}=-195 \mathrm{~m}$, $80 \mathrm{~km} / \mathrm{h}$, in the up direction).

In the down direction, the train passing by the bridge with $X_{2}=-445 \mathrm{~m}$ and a speed of $80 \mathrm{~km} / \mathrm{h}$ is also studied. The corresponding calculation conditions are listed in Table 4. The time history curves of the lateral and vertical acceleration, the first wheelset force, the wheel unloading rate, and derailment coefficient of the first car of the train, the trailer, and the second car of the train, the motor car, are shown in Figures 15 and 16. As shown in Figure 15, the maximum value of the trailer's lateral acceleration appears at $12.9 \mathrm{~s}$ and equals $0.7805 \mathrm{~m} / \mathrm{s}^{2}$. In addition, the first wheelset force and derailment coefficient of the trailer reach their maximum values at $16.5 \mathrm{~s}$, which are 2.16 and 2.02 times larger than
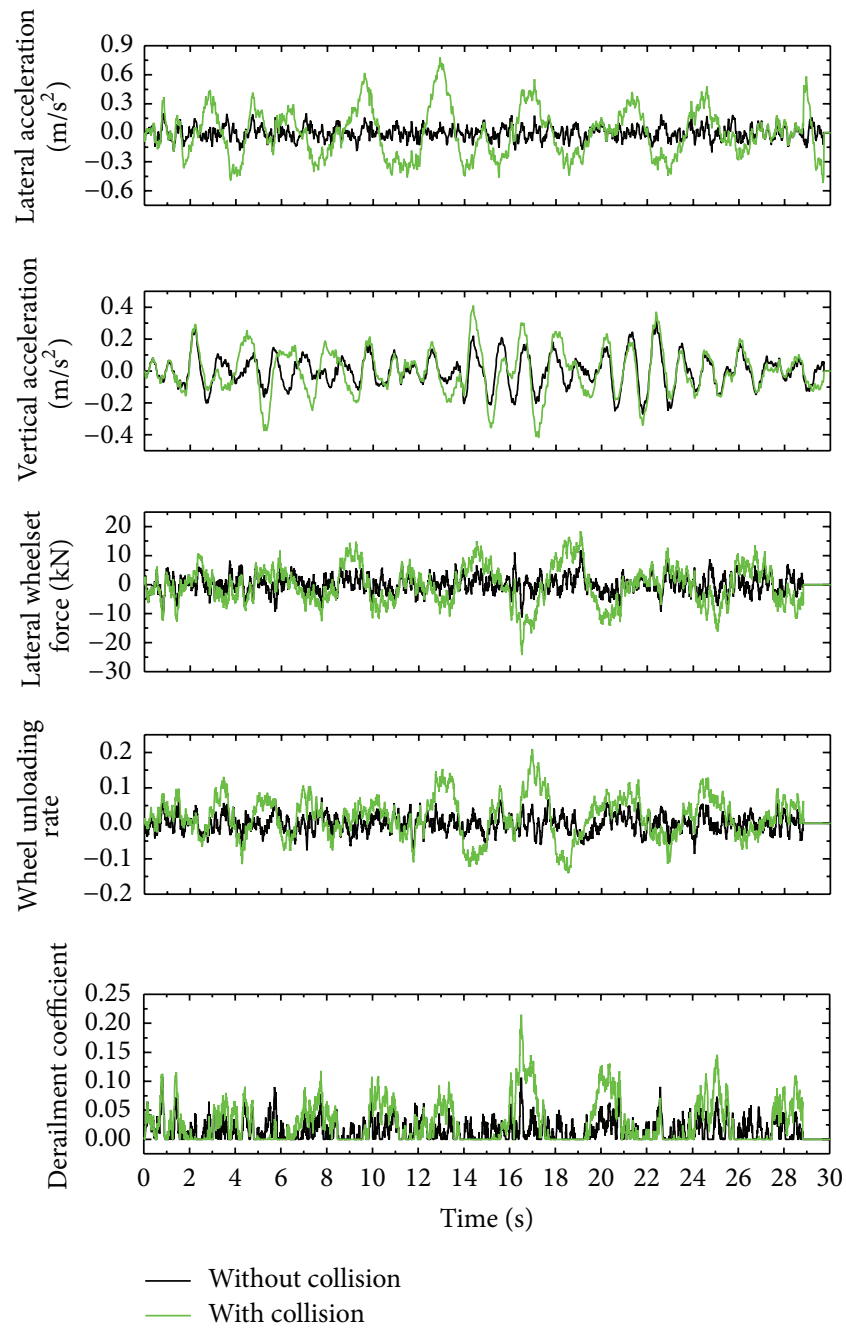

FIGURE 15: Responses of the trailer (the first train, $X_{2}=-445 \mathrm{~m}$, $80 \mathrm{~km} / \mathrm{h}$, in the down direction).

those without collision, respectively. At the same time, the maximum values of the trailer's lateral acceleration and wheel unloading rate are 3.84 and 2.43 times larger than those without collision, respectively. As shown in Figure 16, the motor's lateral acceleration reaches the maximum value at $12.85 \mathrm{~s}$ and equals $0.7805 \mathrm{~m} / \mathrm{s}^{2}$. In addition, the first wheelset force and derailment coefficient of the motor reach the maximum values at $20.31 \mathrm{~s}$. And the maximum values of the lateral acceleration, the first wheelset force, the wheel unloading rate, and derailment coefficient of the motor are $3.37,1.92,2.69$, and 1.71 times larger than those without the collision, respectively. 

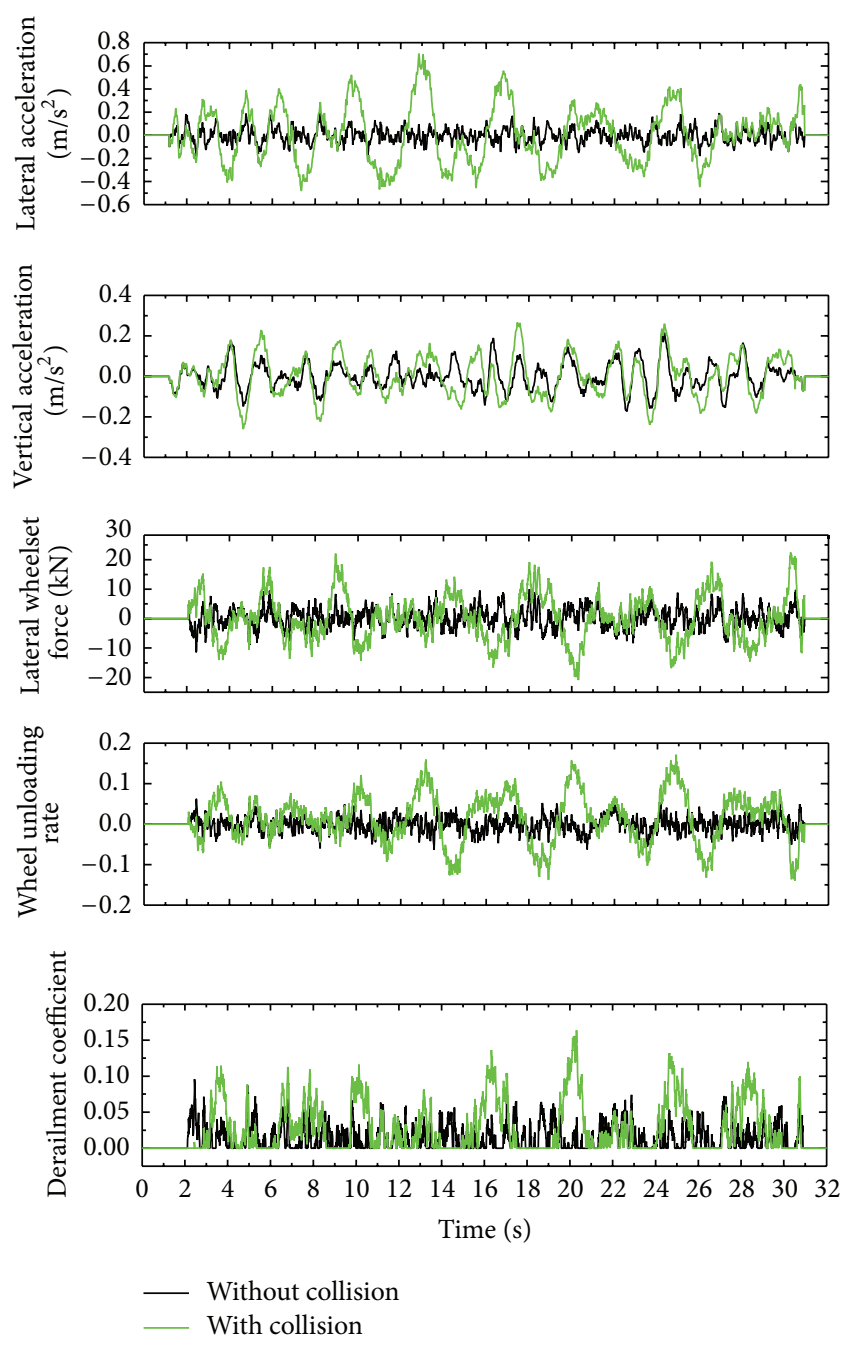

FIgURE 16: Responses of the motor car (the second train, $X_{2}=$ $-445 \mathrm{~m}, 80 \mathrm{~km} / \mathrm{h}$, in the down direction).

\section{Parameter Analysis}

4.1. Train's Position as Collision. With the difference of $X_{2}$, the train's position on the bridge as collision, the maximum responses of the train are different. Figure 17 shows the maximum values of the lateral and vertical acceleration, lateral wheelset force, wheel unloading rate, and derailment coefficient of the train subjected to collision at various places. It is shown that the maximum responses can be described by oblique upward wavy lines. Meanwhile, the values become very large when the train is located between $-70 \mathrm{~m}$ and $30 \mathrm{~m}$ in coincidence with the collision. The derailment coefficient of the train exceeds 0.8 greatly and reaches its upper limit, at which the computation is no longer convergent. It can be concluded that these positions can be considered as the dangerous zone for the trains. And derailment will occur if the bridge is collided by a $3500 \mathrm{t}$ ship with a speed of $3 \mathrm{~m} / \mathrm{s}$.

4.2. The Tonnage of the Vessel. There are two kinds of curves shown in Figure 18 recording the maximum responses of the
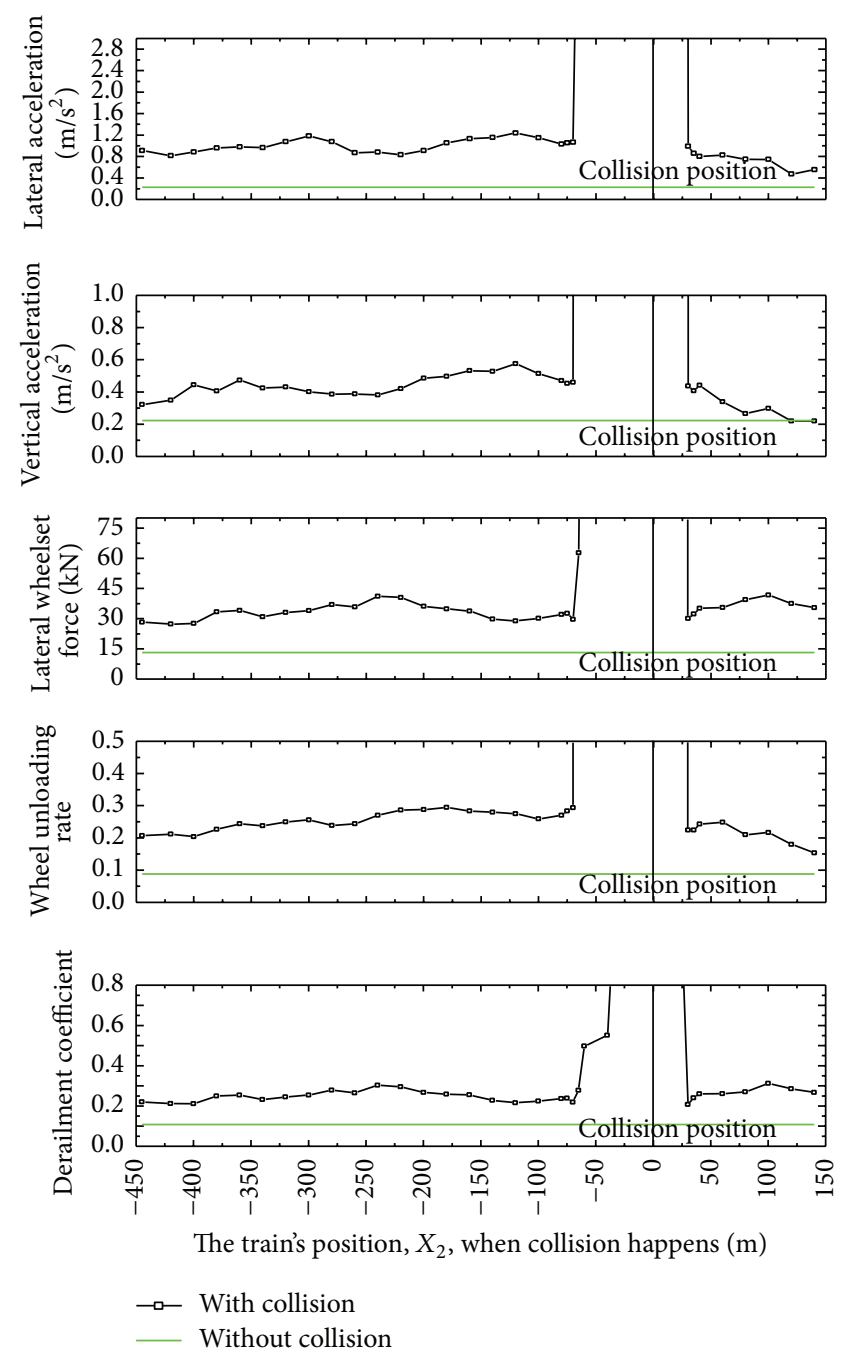

FIGURE 17: Influence of the train's position when collision happens.

train on the different location of the bridge under different collision force from ships, of which the tonnages are $1000 \mathrm{t}$ and $3500 \mathrm{t}$. From this figure, the influence of the ship tonnage on the responses of the train is obvious. The smaller the tonnage of the collision vessel is, the more the maximum of the train's responses moves towards these without collision. And oblique upward wavy lines can also fit well with the results from the $1000 \mathrm{t}$ ship collision, under which the dangerous region of the train is between $-13 \mathrm{~m}$ and $30 \mathrm{~m}$. Therefore, it can be concluded that the dangerous region is associated with the ship tonnage.

4.3. Train's Speed. The maximum responses of the train with 5 speeds at two different positions of the bridge under a $3500 \mathrm{t}$ ship collision are shown in Figure 19. From the displacement field of the bridge subjected to the collision, the lateral displacement which is far from the impact location is relatively small. When the collision happens and the train happens to cross the bridge, the maximum responses of the train increase 

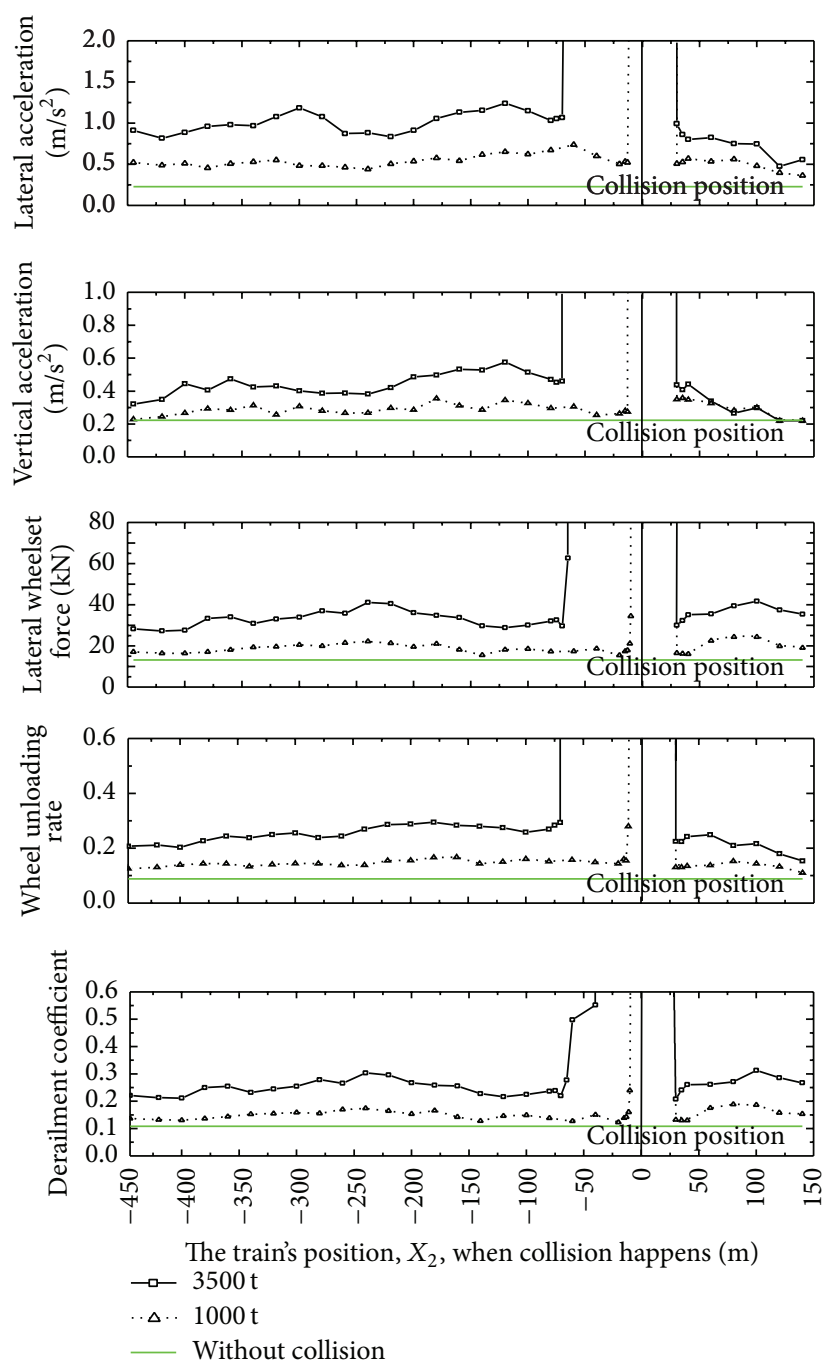

FIGURE 18: Influence of the tonnage of the ship.

with the increase of the train speed. This feature is close to that of the vehicle-bridge coupling without collision [28]. When the collision occurs and the train happens to arrive in the mid-span of the bridge (in the down direction), the effect of the vessel-bridge collision becomes larger, and the change law of the maximum values of train's responses is not in keeping with the increase of the speed well. As the speed increases, the maximum lateral acceleration becomes larger; the maximum vertical acceleration increases under train speed less than $80 \mathrm{~km} / \mathrm{h}$ and then becomes smaller when the train speed is greater than $80 \mathrm{~km} / \mathrm{h}$; the maximum lateral wheelset force and wheel loading rate firstly increase and then decrease when the train speed is less than $80 \mathrm{~km} / \mathrm{h}$ and become larger under train speed larger than $80 \mathrm{~km} / \mathrm{h}$; and the maximum derailment coefficient decreases under train speed less than $80 \mathrm{~km} / \mathrm{h}$ and firstly increases and then decreases when the train speed is greater than $80 \mathrm{~km} / \mathrm{h}$. From the analysis above, the effect of train's speed on the running safety of trains under vessel-collision force is complex resulting from the position and the staying time of the train. When the collision happens and the train starts to cross the bridge in the sense that the train is far away from the collision, it is more dangerous as the train accelerates. But when the collision occurs and the train happens to arrive in the mid-span of the bridge in the sense that the train is close to the collision, low speed does not imply great safety of the train. When the speed is at a relatively low level, the train may remain on the bridge for a longer time, which could increase the effect of ship collision on train's responses.

\section{Conclusions}

The following conclusions can be obtained from the study.

(1) The vessel-bridge collision causes the significant increase of the train's lateral acceleration, lateral wheelset force, wheel unloading rate, and derailment coefficient. These indices are nearly $3.8,2.1,2.5$, and 1.8 times those without collision, respectively, when a train passes the bridge under vessel-collision force. Yet the effect of the collision on the train's vertical acceleration is much smaller.

(2) The lateral displacement of the girder close to the collision position (in the down direction) is relatively larger. In addition, the driving condition is associated with the structure form of the approach bridge. Conversely, the lateral displacement far from the impact position (in the down direction) is relatively smaller, and the driving condition here is good as well. Therefore, it has difference in train's response according to the direction into the bridge.

(3) The maximum responses of the train at different positions of the bridge can be described by oblique upward wavy lines. For the train, the closer it is to the collision position, the more dangerous it will be. At the same time, there is a dangerous zone for the moving train. When the bridge is subjected to the collision, it is possible for the train to derail when it happens to come into this zone.

(4) The larger the tonnage of the collision ship is, the greater the train's responses are, the bigger the dangerous zone is, and the worse the running safety is.

(5) The effect of train's speed on the running safety of trains under vessel-collision force is complex resulting from the position and the staying time of the train. There is a relatively high probability of running danger at a lower speed under vessel-bridge collision, resulting from longer stay of the train on the bridge.

\section{Conflict of Interests}

The authors declare that there is no conflict of interests regarding the publication of this paper.

\section{Acknowledgments}

The authors are grateful to the financial supports from the National Natural Science Foundation of China (U1334201 


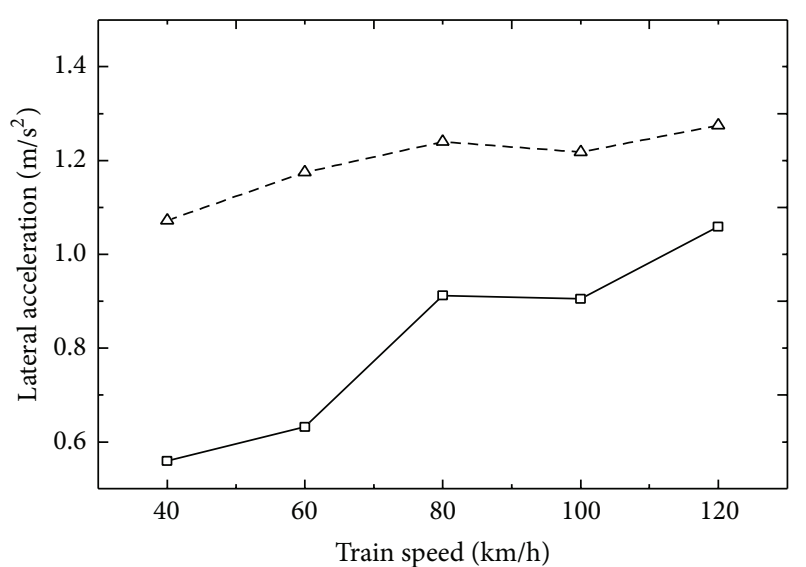

(a) Lateral acceleration

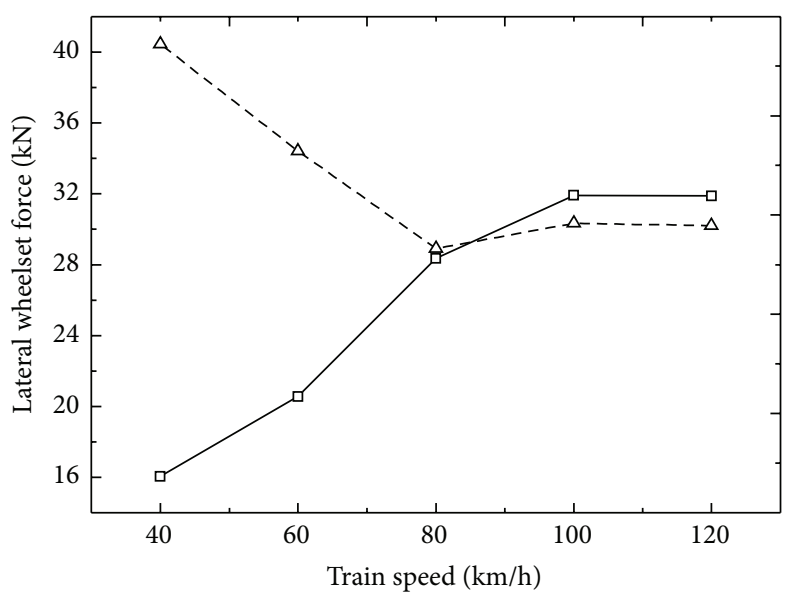

(c) Lateral wheelset force

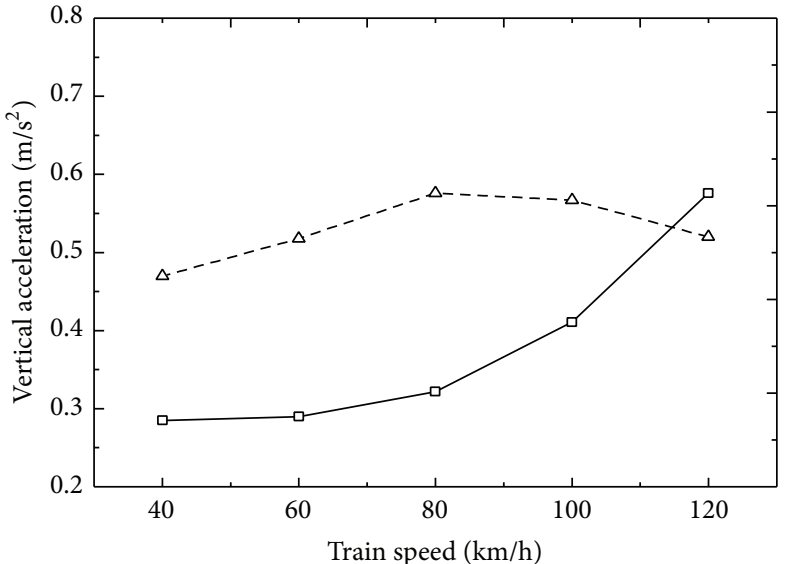

(b) Vertical acceleration

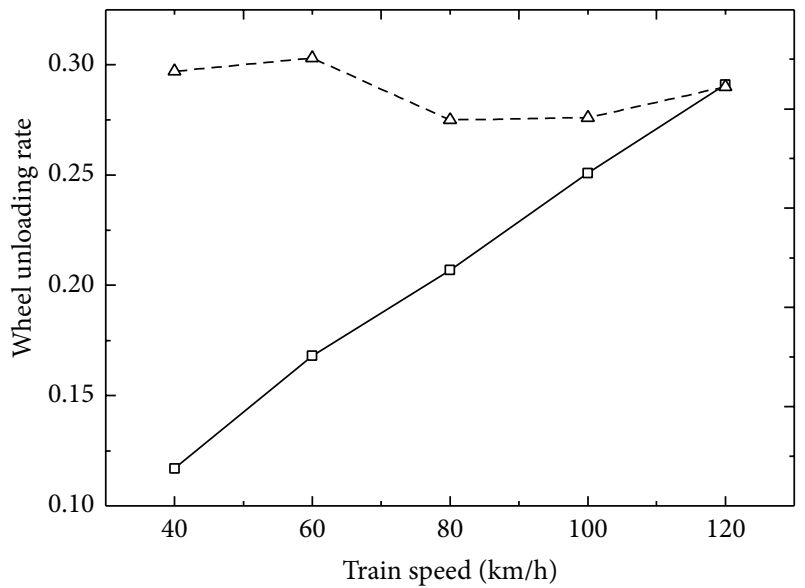

(d) Wheel unloading rate

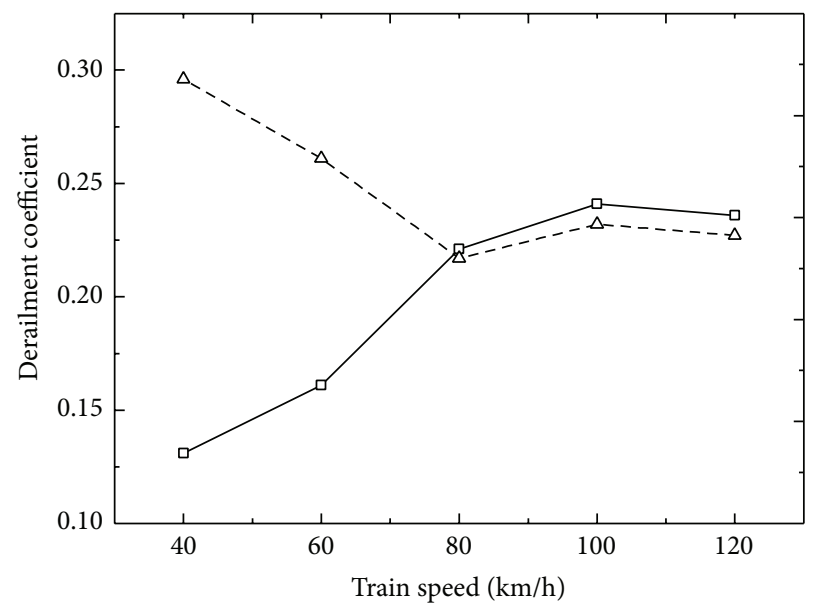

$\rightarrow-$ Train at the bridge entrance

$-\Delta-$ Train at the bridge mid-span

(e) Derailment coefficient

FIGURE 19: Influence of the train's speed. 
and 51278434), the National Key Basic Research Development Plan of China (2013CB036206), and the Sichuan Province Youth Science and Technology Innovation Team (15CXTD0005).

\section{References}

[1] B. Chen, Z. W. Chen, Y. Z. Sun, and S. L. Zhao, "Condition assessment on thermal effects of a suspension bridge based on SHM oriented model and data," Mathematical Problems in Engineering, vol. 2013, Article ID 256816, 18 pages, 2013.

[2] H. N. Li, T. H. Yi, L. Ren, D. S. Li, and L. S. Huo, "Reviews on innovations and applications in structural health monitoring for infrastructures," Structural Monitoring and Maintenance, vol. 1, no. 1, pp. 1-45, 2014.

[3] Z. W. Chen, Y. L. Xu, and X. M. Wang, "SHMS-based fatigue reliability analysis of multiloading suspension bridges," Journal of Structural Engineering, vol. 138, no. 3, pp. 299-307, 2012.

[4] T. H. Yi, H. N. Li, and X. D. Zhang, "Sensor placement on Canton Tower for health monitoring using asynchronous-climb monkey algorithm," Smart Materials and Structures, vol. 21, no. 12, Article ID 125023, pp. 1-12, 2012.

[5] T. H. Yi, H. N. Li, and M. Gu, "Experimental assessment of high-rate GPS receivers for deformation monitoring of bridge," Measurement, vol. 46, no. 1, pp. 420-432, 2013.

[6] Ministry of Railyways of the People's Republic of China, Fundamental Code for Design on Railway Bridge and Culvert (TB10002.1-2005), 2005, (Chinese).

[7] T. Y. Dai, Ship Impact Against Bridge and Its Risk Assessment, Harbin Engineering University, 2002.

[8] G. R. Consolazio and D. R. Cowan, "Numerically efficient dynamic analysis of barge collisions with bridge piers," Journal of Structural Engineering, vol. 131, no. 8, pp. 1256-1266, 2005.

[9] P. T. Pedersen and S. Zhang, "The mechanics of ship impacts against bridges," in Ship Collision Analysis: Proceedings of the International Symposium on Advances in Ship Collision Analysis, Copenhagen, 1st January 1998, pp. 41-51, Balkema Publishers, A.A./Taylor \& Francis, Rotterdam, The Netherlands, 1998.

[10] W. J. Liang and G. Z. Cheng, "Ship collision force and energy absorbability," Journal of SSSRI, no. 2, pp. 23-34, 1992 (Chinese).

[11] F. Yetal, "Some factors affecting the frequency of accidents in marine traffic," Journal of Navigation, vol. 27, pp. 235-252, 1974.

[12] Ship Collision due to the Presence of Bridges, "Report of Working Group 19 of the Inland Navigation Commission," 2001.

[13] AASHTO, LRFD Bridge Design Specification and Commentary American Association of State Highway and Transportation Officials, Washington, DC, USA, 1994.

[14] A. C. W. M. Vrouwenvelder, "Design for Ship Impact according to Euroeode 1 Part 2.7," Ship Collision Analysis, 1998.

[15] C. U. Kunz, "Ship bridge collision in river traffic analysis and design practice," in Ship Collision Analysis, 1998.

[16] O. D. Larsen, "Ship Collision with Bridge," ABSE Structural Engineering Documents, 1993.

[17] C. L. Chen, R. X. Gao, and H. P. Zhu, "Substructure responses and damage assessment of on building bridge under shipbridge collision," in The 20th National Structural Engineering Conference Proceedings, II book, 2011, (Chinese).

[18] G. R. Consolazio and D. R. Cowan, "Nonlinear analysis of barge crush behavior and its relationship to impact resistant bridge design," Computers and Structures, vol. 81, no. 8-11, pp. 547-557, 2003.
[19] J. J. Wang and C. Chen, "Simulation of damage for bridge pier subjected to ship impact," Engineering Mechanics, vol. 24, no. 7, pp. 156-160, 2007.

[20] H. Lenselink, K. G. Thung, and H. I. Stipdonk, "Numerical simulations of ship collisions," in Proceedings of the 2nd International Offshore and Polar Engineering Conference, pp. 79-88, June 1992.

[21] E. Lehmann and J. Peschmann, "Energy absorption by the steel structure of ships in the event of collisions," Marine Structures, vol. 15, no. 4-5, pp. 429-441, 2002.

[22] Y. Y. Sha and H. Hao, "Nonlinear finite element analysis of barge collision with a single bridge pier," Engineering Structures, vol. 41, pp. 63-76, 2012.

[23] H. Xia, Y. Han, N. Zhang, and W. Guo, "Dynamic analysis of train-bridge system subjected to non-uniform seismic excitations," Earthquake Engineering and Structural Dynamics, vol. 35, no. 12, pp. 1563-1579, 2006.

[24] Y. B. Yang and Y. S. Wu, "Dynamic stability of trains moving over bridges shaken by earthquakes," Journal of Sound and Vibration, vol. 258, no. 1, pp. 65-94, 2002.

[25] C. Y. Xia, H. Xia, and G. De Roeck, "Dynamic response of a train-bridge system under collision loads and running safety evaluation of high-speed trains," Computers and Structures, vol. 140, pp. 23-38, 2014.

[26] W. W. Zhang, X. L. Jin, and J. W. Wang, "Numerical analysis of ship-bridge collision's influences on the running safety of moving rail train," Ships \& Offshore Structures, vol. 9, no. 5, pp. 498-513, 2014.

[27] Y. Li, S. Qiang, H. Liao, and Y. L. Xu, "Dynamics of windrail vehicle-bridge systems," Journal of Wind Engineering and Industrial Aerodynamics, vol. 93, no. 6, pp. 483-507, 2005.

[28] Y. Zhou, Simulation of vehicle-bridge coupling vibration based on ANSYS and SIMPACK [M.S. thesis], Southwest Jiaotong University, 2013. 

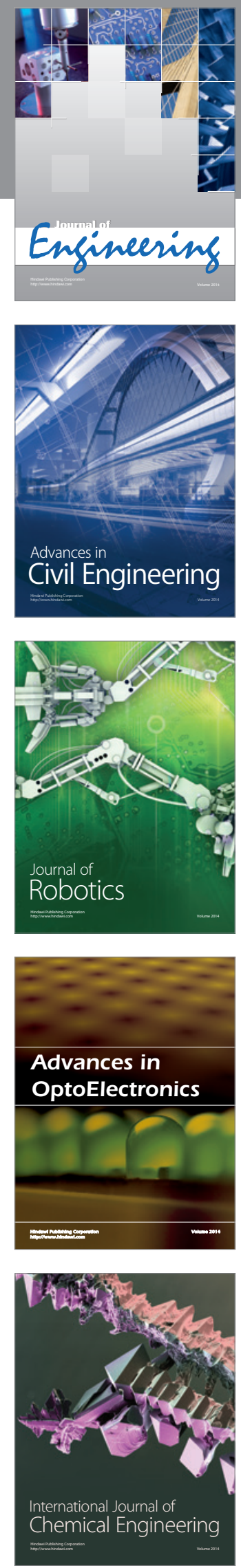

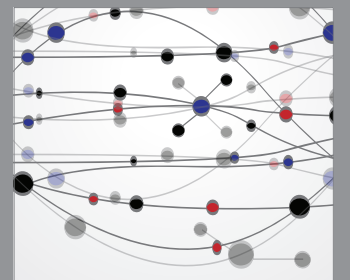

The Scientific World Journal
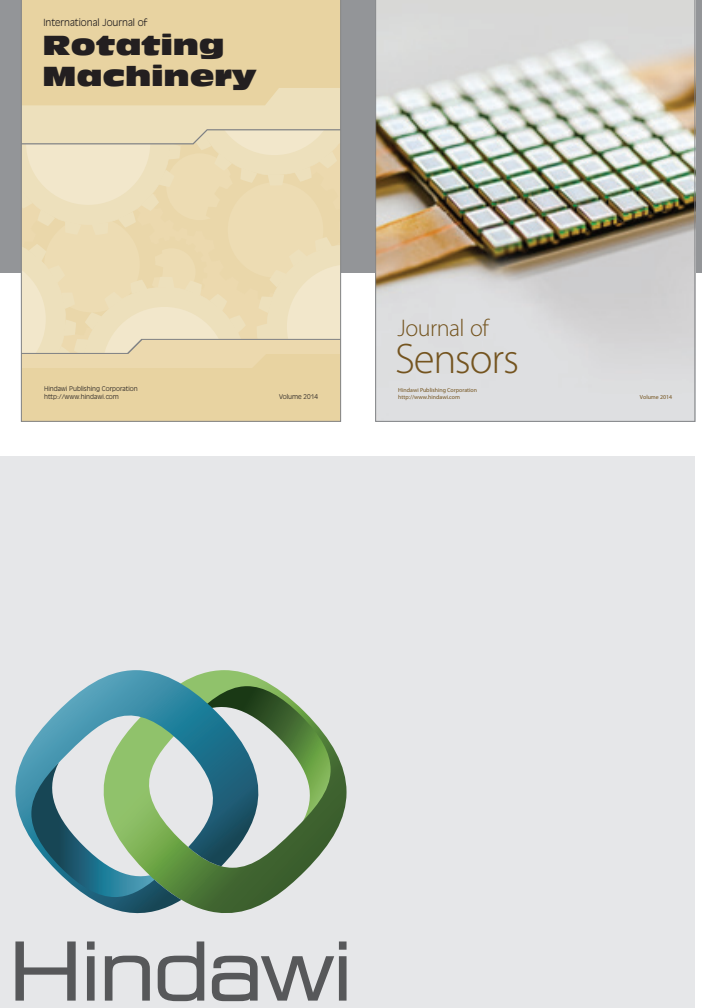

Submit your manuscripts at http://www.hindawi.com
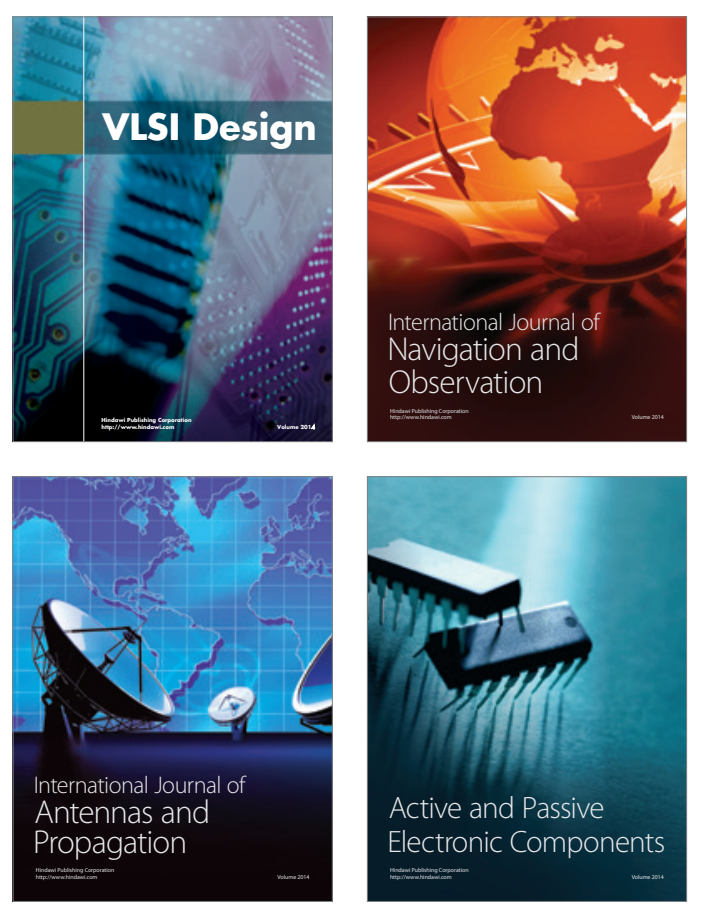
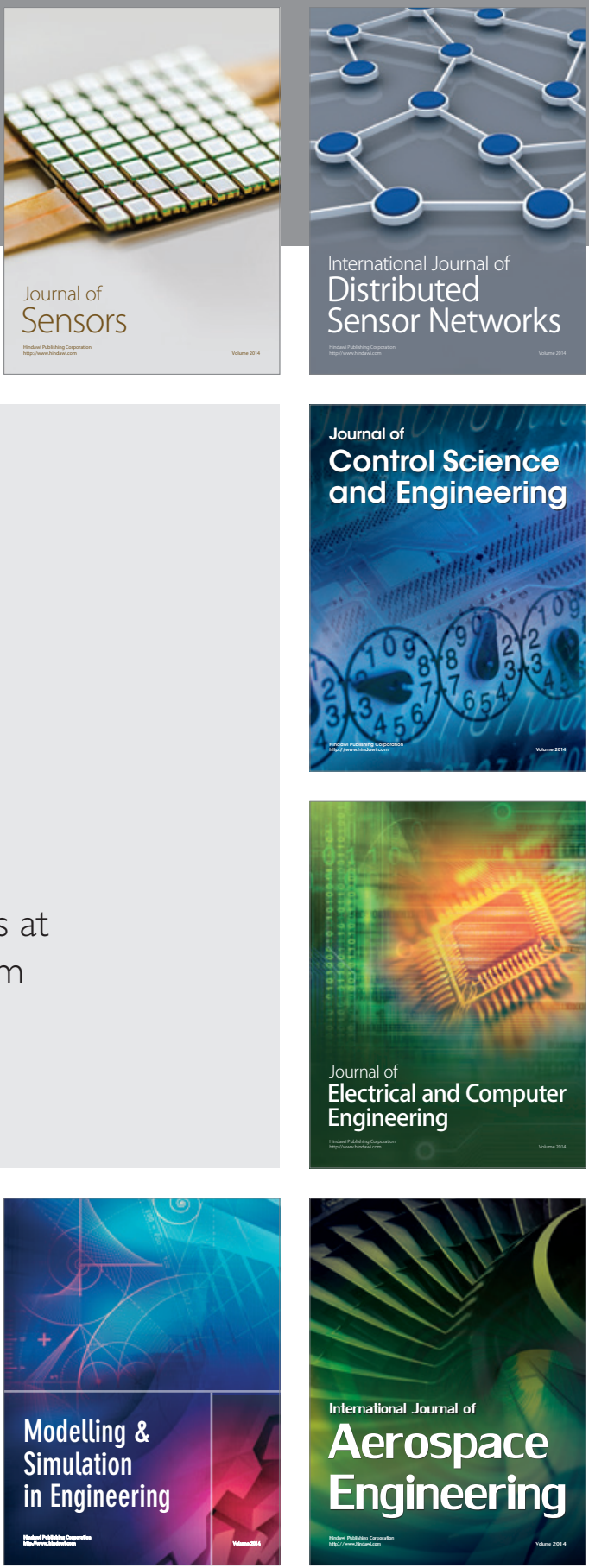

Journal of

Control Science

and Engineering
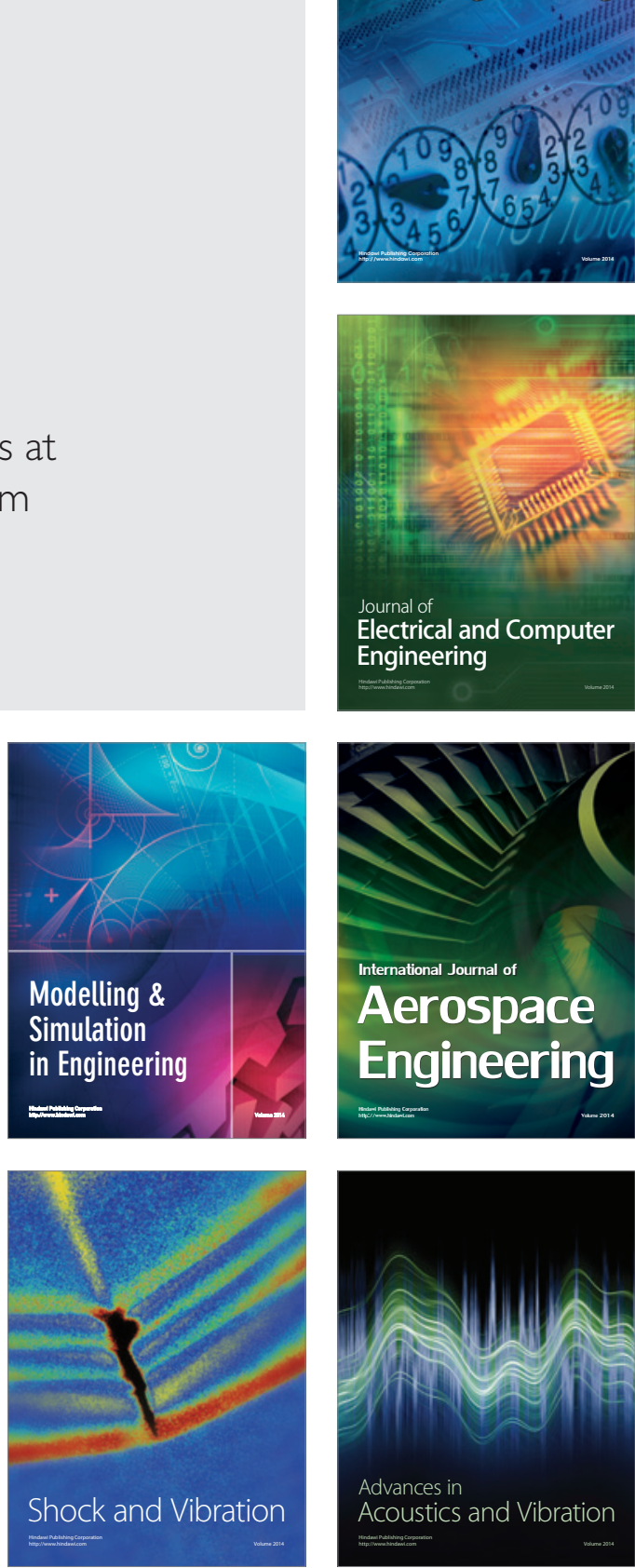